\title{
DEVELOPMENT OF A TRAINING Platform on Domestic VIOLENCE
}

\author{
BetTina Pfleiderer \& Paulina Juszczyk \\ Westfalian Wilhelm-University Münster, Faculty of Medicine, Münster, Germany. \\ E-mail: pfleide@wwu.de; paulina.juszczyk@wwu.de
}

Abstract As part of the IMPRODOVA project, a training platform with training formats and materials was designed to optimise front-line response strategies and enhance interorganisational cooperation to prevent, investigate and mitigate domestic violence. The teaching concept involved two pillars: training platform can either be used as an online self-learning tool to train oneself individually combined with knowledge assessment, case studies and training videos or as a source for training materials on domestic violence for trainers who want to conduct a training on domestic violence on their own. The chapter explains the needs identified through the IMPRODOVA research and requests from front-line responders, focusing on the most relevant topics for the police, the health and the social sector. The training materials specially designed for this training platform and tailored to each domestic violence responder group are presented. The chapter addresses the challenge that even though the English international platform provides a good overview on the EU level and corresponding policies, it does not necessarily reflect national/local context and reference frameworks. The chapter concludes with a description of the evaluation results of the IMPRODOVA training platforms and highlights gaps to improve the platform's usability.

Keywords: training platform, domestic violence, Europe, police, social work, health sector, IMPRODOVA 


\section{Training platform on domestic violence}

As part of the IMPRODOVA project, a training platform with training formats and materials was designed to optimise frontline response strategies and enhance interorganisational cooperation to prevent, investigate and mitigate domestic violence.

A freely accessible online training platform is a low-threshold measure to reach frontline responders. Scenario-based learning and case studies, workshop concepts and presentations, educational videos tailored to the various frontline responders, as well as guidelines to enhance frontline responders' cooperation across different professions were integrated as basic material to elaborate and illustrate training modules. To sensitise the various frontline responders from the police, the health sector and the social sector, a special focus was put on how to detect signs of domestic violence.

Table 1 provides the main links to all modules/sections of the platform. Training materials related to various topics of interest can be easily found by using the "Search" function on the platform.

Table 1: Link list for the webpages on the international training platform

\begin{tabular}{ll}
$\begin{array}{l}\text { IMPRODOVA training } \\
\text { platform }\end{array}$ & Link \\
\hline $\begin{array}{l}\text { International training } \\
\text { platform }\end{array}$ & https://training.improdova.eu/ \\
\hline German training platform & https://training.improdova.eu/de/ \\
\hline $\begin{array}{l}\text { Introduction - Police as } \\
\text { frontline responder to } \\
\text { domestic violence }\end{array}$ & $\begin{array}{l}\text { https://training.improdova.eu/en/introduction-police-as- } \\
\text { frontline-responder-to-domestic-violence/ }\end{array}$ \\
\hline $\begin{array}{l}\text { Introduction - Domestic } \\
\text { violence in the Health } \\
\text { Sector }\end{array}$ & $\begin{array}{l}\text { https://training.improdova.eu/en/introduction-domestic- } \\
\text { violence-in-the-health-sector/ }\end{array}$ \\
\hline $\begin{array}{l}\text { Introduction - Domestic } \\
\text { violence in the Social }\end{array}$ & $\begin{array}{l}\text { https://training.improdova.eu/en/introduction-domestic- } \\
\text { violence-in-the-social-sector/ }\end{array}$ \\
Sector & $\begin{array}{l}\text { https://training.improdova.eu/en/training-modules-for- } \\
\text { the-police/ }\end{array}$ \\
Police & $\begin{array}{l}\text { https://training.improdova.eu/en/training-modules-for- } \\
\text { the-health-sector/ }\end{array}$ \\
\hline $\begin{array}{l}\text { Training modules for the } \\
\text { Health Sector }\end{array}$ & $\begin{array}{l}\text { https://training.improdova.eu/en/training-modules-for- } \\
\text { the-social-sector/ }\end{array}$ \\
\hline $\begin{array}{l}\text { Training modules for the } \\
\text { Social Sector }\end{array}$ & \\
\hline
\end{tabular}




\begin{tabular}{ll}
$\begin{array}{l}\text { IMPRODOVA training } \\
\text { platform }\end{array}$ & Link \\
\hline Data and statistics & https://training.improdova.eu/en/data-and-statistics/ \\
\hline $\begin{array}{l}\text { Training materials for the } \\
\text { Police }\end{array}$ & $\begin{array}{l}\text { https://training.improdova.eu/en/training-materials-for- } \\
\text { the-police/ }\end{array}$ \\
\hline $\begin{array}{l}\text { Training materials for the } \\
\text { https://training.improdova.eu/en/training-materials-for- } \\
\text { Health Sector }\end{array}$ & $\begin{array}{l}\text { the-health-sector/ } \\
\text { https://training.improdova.eu/en/training-materials-for- } \\
\text { Training materials for the } \\
\text { Social Sector }\end{array}$ \\
\hline
\end{tabular}

\section{Preparation phase}

The development of the platform involved three phases with some of the phases overlapping (Figure 1). In Phase 1, research was done in the EU project IMPRODOVA by analysing policy implementation, legislation, data, risk assessment, case documentation, cooperation, and trainings.

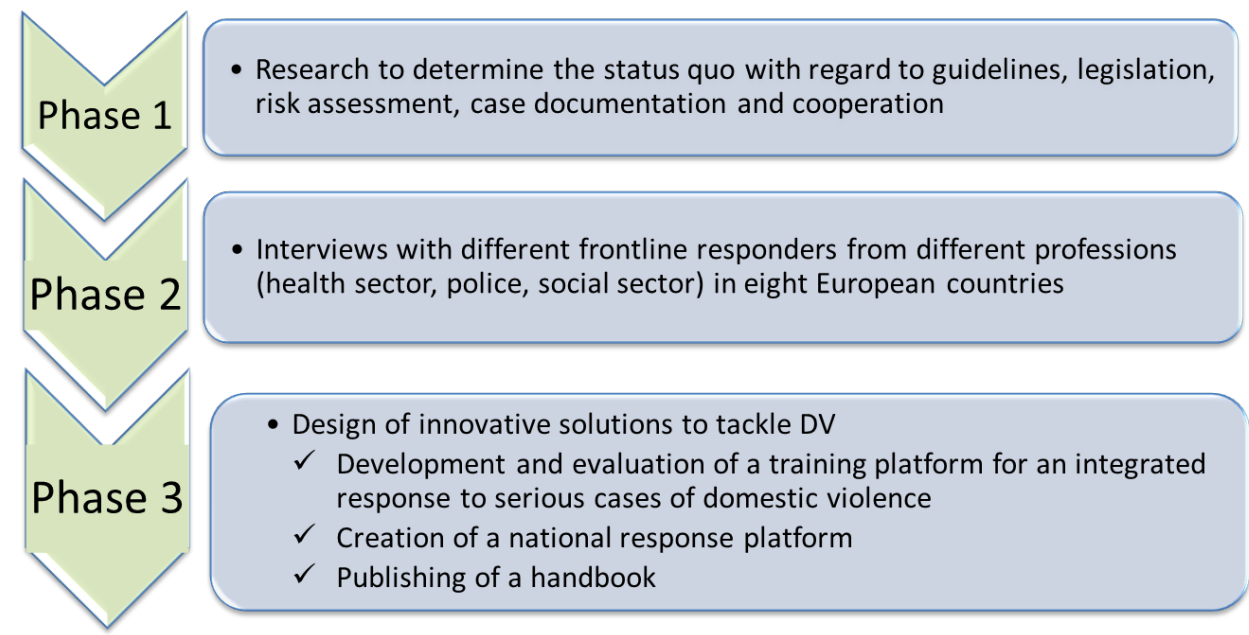

Figure 1: Phases of the IMPRODOVA project

This was complemented in phase 2 by the analysis of 296 interviews with different frontline responders from police, the health sector, and the social sector in eight European countries to investigate frontline responder practices with a special emphasis on inter-agency cooperation. It was also assessed to the extent to which standards are converted into practice (Herbinger et al., 2020) and actors are involved in multi-professional approaches to tackle domestic violence (Vogt, 2020). 
After analysing the interviews, it became clear that the main challenge is to meet the needs of different frontline responder groups in different countries, as well as to tackle gaps in their understanding of their roles in fighting domestic violence (DV), and finally, to improve inter-agency cooperation. The interviews also provided important country-specific information about frontline responders' training provisions which already exist and could be further optimised. The objective was to gain more insight into the country-specific domestic violence training and education for frontline responders to see gaps, good practices, or possibilities for improvement. A great availability of various education and training formats could be identified (Houtsonen, 2020). For example, health professionals are often the first point of contact for victims of domestic violence and thus, play a major role in the detection and intervention of domestic violence. Interviews with professionals from the medical sector within the IMPRODOVA project indicated that they are not sufficiently trained in handling domestic violence cases and are not aware of their role as frontline responders in domestic violence cases. It also became clear that interagency collaboration was lacking (Pfleiderer \& Sondern, 2021). Yet, one of the most important goals in the fight against domestic violence is to have all frontline responder groups (e.g., the police, the medical profession, social work, victim protection shelters, law enforcement, and counselling centres) actively involved at all levels to draw more victims into existing help networks and to deal with a case comprehensively.

In phase 3, it was decided to design a freely available online training platform on domestic violence in addition to a national response platform (chapter 4.1.) and writing a book on DV. A main challenge emerged: even though the international English platform provides a good overview of the EU level and corresponding policies, it does not necessarily reflect national/local context and reference frameworks. As a best practice model for a local/national version of the training platform a German IMPRODOVA training platform was developed, which, even though the main content was based on the English international platform, was tailored and adapted to the local German context and needs. 


\section{Concept of the training platform on DV}

We decided to present our teaching material in the form of building blocks with various modules being made available to the different stakeholder groups - police, health sector, social sector - and materials tailored to the situation in different countries. The teaching concept involved two pillars: the training platform could either be used as an online self-learning tool to train oneself individually combined with knowledge assessment, case studies and training videos or as a source for training materials on DV for trainers/teachers who want to conduct a training on domestic violence on their own.
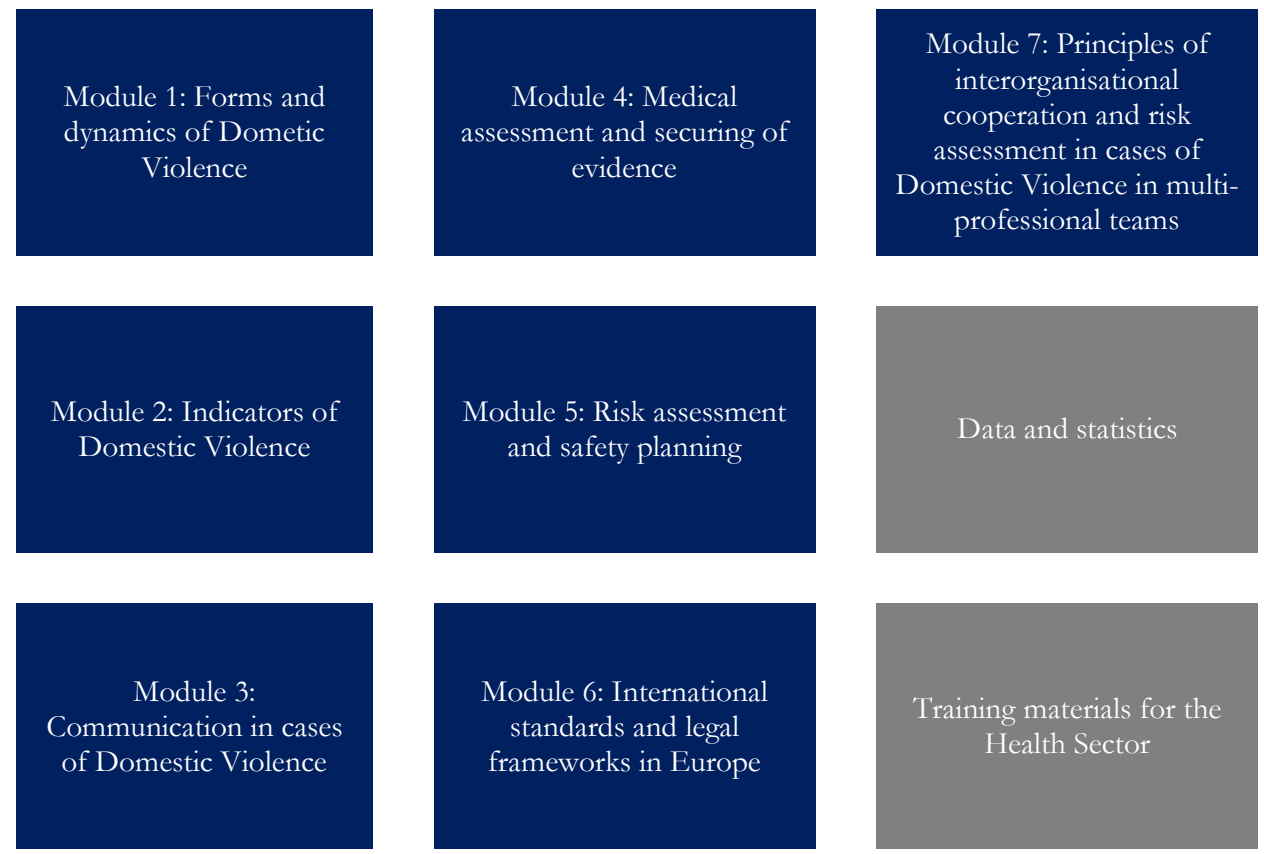

Figure 2: Modular concept of the training platform - exemplary screenshot for the medical sector

For the building blocks, partners of the IMPRODOVA consortium were asked to provide country-specific information and case scenarios and knowledge assessment questions by completing a template with several feedback cycles to further optimise the provided information. Information was organised in seven modules and three additional sections - data and statistics, teaching materials and introductions were added as well (Figure 2). The introductions for the police, the health sector, and the 
social sector summarise the most important information for the three frontline responders being no experts in DV, hereby considering the limited time resources of practitioners. The seven modules are thematically the same, but the content is tailored to the needs of each sector.

\section{Specific training needs of the various frontline responders}

\section{Specifics for the police}

Interviews in the IMPRODOVA project indicate that not all police officers may have adequate competencies to deal with domestic violence. Therefore, when cases of domestic violence arise, police officers often feel frustrated and discontent. As a result, victims may feel not being sufficiently supported or protected, so that they neither report the violence they have experienced nor seek help. Police officers who handle such cases would benefit from a gender-sensitive training on DV and risk assessment.

Based on our findings, risk is assessed by non-standardised procedures and frequently based on a "gut feeling". Often gender aspects are not integrated sufficiently in existing risk assessment tools and procedures. This leads to an increased likelihood that police officers will overlook male victims of domestic violence in intimate relationships. Gendered perceptions bear the risk of revictimising the victim or to not take the victims' complaints seriously. This might be responsible for victims not sharing all information that are relevant for the risk assessment. Police officers must therefore be trained to reflect their own behaviour and judgement, because sex and gender aspects may not only affect the questions being asked but also how the questions are being asked and how the answers will be interpreted by those asking (Pfleiderer \& Sondern, 2020). Furthermore, training should enable police officers to be more open to inter-organisational cooperation in order to meet the various needs of the victims (Houtsonen, 2020).

Accordingly, IMPRODOVA training materials tailored to the police include gendersensitive communication and risk assessment. Recommendations for innovative gender-sensitive trainings and education for various frontline responder groups follow in the next chapter 4.3. 


\section{Specifics for the health sector}

Short and long-term health consequences of domestic violence prompt victims to seek help from the medical profession. Interviews with health professionals in the IMPRODOVA countries revealed that not all of them have been sufficiently trained in the area of domestic violence. In most European countries, knowledge about domestic violence, symptoms and red flags are not regularly part of the mandatory curriculum, neither for physicians nor for medical students. Therefore, many health professionals may not be aware of the important role they play in the network. Instead, they see their role primarily in taking care of the medical needs of their patients and rarely consider themselves as frontline responders to domestic violence. A better understanding of their own role, but also of the roles of other frontline responders is a prerequisite in order to work together against domestic violence and to help and assist victims (Pfleiderer \& Sondern, 2021).

Usually, physicians due to their tight schedules, consider extended communication with victims about their experiences of domestic violence as almost impossible. The aim of the section on our training platform for the medical sector "Introduction Domestic violence in the Health Sector" aims to support practitioners in identifying patients and their children who have been victims of domestic violence and to respond to them appropriately in as little time as possible.

\section{Specifics for the social sector including the school system}

Frontline responders' feedback revealed that professionals from the social sector usually play the role of training providers rather than as beneficiaries of a training. Participation in training is cost-intensive and consequently, the costs cannot be covered by employers. Social sector professionals are comparatively well trained in the area of domestic violence. What they lack are practical examples and precise instructions for their activities, e.g., to assess the risk of domestic violence. Practical examples specially tailored to the social sector have been added to the training platform. We also included concise recommendations for teachers on how to deal with (suspected) cases of domestic violence at school (Figure 3). 


\section{Recommendations on how to proceed in cases of suspected domestic violence}
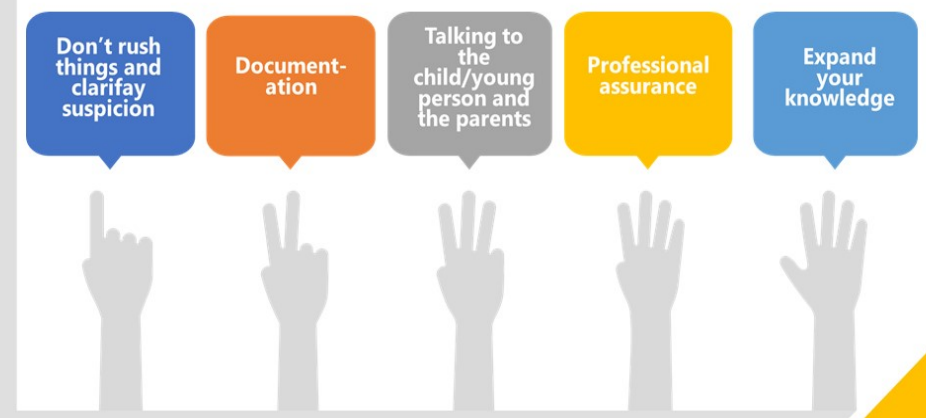

Figure 3: Recommendations on how to proceed in cases of suspected domestic violence for school teachers to be found in module 2 for the social sector

As visible injuries, behavioural problems, or changes in behaviour of a child or adolescent may raise the suspicion that domestic violence could be present in a family, educators, school social workers and teachers need to be sensitised to this. In any case, the primary goal should be to end the violence against a child, an adolescent, or a parent. In most domestic violence cases, the best way to help the child or the adolescent is for the parent itself to change the situation. Encouraging parents to do so and giving them access to help is important in the school sector.

\section{Training modules of the platform}

Based on the needs identified through the IMPRODOVA research and requests from frontline responders, the platform includes a section on DV data and statistics, as well as seven modules focused on the topics most relevant for frontline responders. (cf. Figure 2): 
Table 2: Overview of the modules included on the IMPRODOVA training platform

\begin{tabular}{|c|c|}
\hline $\begin{array}{l}\text { Module 1: Forms and } \\
\text { dynamics of domestic violence }\end{array}$ & $\begin{array}{l}\text { Module } 1 \text { aims at a better understanding of } \\
\text { Domestic Violence, its forms, and consequences. } \\
\text { Knowledge is transmitted about the specific context } \\
\text { and the impact of domestic violence that can be a } \\
\text { helpful step in understanding the individual needs of } \\
\text { victims. }\end{array}$ \\
\hline $\begin{array}{l}\text { Module } 2: \text { Indicators of } \\
\text { domestic violence }\end{array}$ & $\begin{array}{l}\text { The objective of Module } 2 \text { is to become familiar with } \\
\text { the various indicators of domestic violence, their } \\
\text { related risks and to get sensitised to them. At this } \\
\text { point, a special focus is put on how to detect signs } \\
\text { of high impact domestic violence. The content is } \\
\text { tailored for police officers, the health sector, and the } \\
\text { social sector. }\end{array}$ \\
\hline $\begin{array}{l}\text { Module 3: Communication in } \\
\text { cases of domestic violence }\end{array}$ & $\begin{array}{l}\text { Module } 3 \text { presents the different ways of asking about } \\
\text { domestic violence in situations where a frontline } \\
\text { responder suspects the incidence of domestic } \\
\text { violence. Furthermore, first steps after the disclosure } \\
\text { of domestic violence are presented. There is a } \\
\text { version for police officers, the health sector, and the } \\
\text { social sector of Module } 3 \text {. }\end{array}$ \\
\hline $\begin{array}{l}\text { Module 4: Police investigation } \\
\text { and legal proceedings }\end{array}$ & $\begin{array}{l}\text { Module } 4 \text { for police officers presents the most } \\
\text { important aspects to be considered in police } \\
\text { investigations and subsequent legal proceedings after } \\
\text { the disclosure of domestic violence. }\end{array}$ \\
\hline $\begin{array}{l}\text { Module 4: Medical assessment } \\
\text { and securing of evidence }\end{array}$ & $\begin{array}{l}\text { Module } 4 \text { for the health sector presents the most } \\
\text { important aspects to be considered after the } \\
\text { disclosure of domestic violence and how to } \\
\text { document domestic violence injuries for court } \\
\text { proceedings. }\end{array}$ \\
\hline $\begin{array}{l}\text { Module 4: Support services of } \\
\text { the social sector }\end{array}$ & $\begin{array}{l}\text { Module } 4 \text { for the social sector presents the support } \\
\text { offered by social services after the disclosure of } \\
\text { domestic violence. Different contact points are } \\
\text { introduced to the reader. }\end{array}$ \\
\hline $\begin{array}{l}\text { Module 5: Risk assessment } \\
\text { and safety planning }\end{array}$ & $\begin{array}{l}\text { Module } 5 \text { presents why risk assessment is such an } \\
\text { important step when tackling domestic violence and } \\
\text { what needs to be considered when assessing the risk } \\
\text { of victims of domestic violence, and what steps are } \\
\text { necessary to improve the safety of victims. Risk } \\
\text { assessment and safety planning is introduced to the } \\
\text { police, the health sector and the social sector adapted } \\
\text { to their working environment. }\end{array}$ \\
\hline $\begin{array}{l}\text { Module 6: International } \\
\text { standards and legal } \\
\text { frameworks in Europe }\end{array}$ & $\begin{array}{l}\text { Module } 6 \text { introduces the international framework in } \\
\text { which the work of frontline responders takes place. } \\
\text { It also presents country-specific regulations in order } \\
\text { to gain an impression of how other European } \\
\text { countries tackle domestic violence. }\end{array}$ \\
\hline
\end{tabular}




\begin{tabular}{|c|c|}
\hline $\begin{array}{l}\text { Module } 7 \text { : Principles of } \\
\text { interorganisational } \\
\text { cooperation and risk } \\
\text { assessment in cases of } \\
\text { domestic violence in multi- } \\
\text { professional teams }\end{array}$ & $\begin{array}{l}\text { The aim of module } 7 \text { is to understand how frontline } \\
\text { responders work and why cooperation in multi- } \\
\text { professional teams is most successful in tackling } \\
\text { domestic violence. This information is introduced } \\
\text { with slightly different content for the police, the } \\
\text { health sector, and the social sector. }\end{array}$ \\
\hline $\begin{array}{l}\text { The section on data and } \\
\text { statistics }\end{array}$ & $\begin{array}{l}\text { This section includes information about } \\
\text { victimisation surveys and police data in the EU as } \\
\text { those sources have made available the most reliable } \\
\text { and extensive domestic violence data. Additionally, } \\
\text { recommendations on good data harmonisation and } \\
\text { consolidation are summarised that should be } \\
\text { regarded in these cases. In order to be able to use the } \\
\text { platform, as planned, a training material kit for } \\
\text { trainers, a section for teaching materials for police } \\
\text { officers, the health sector and the social sector } \\
\text { completed the platform. }\end{array}$ \\
\hline
\end{tabular}

\section{Design of innovative training materials}

In addition to the modules, the platform was complemented by training material specially designed for this training platform and tailored to each DV responder group. Based on the information of the training platform, downloadable fact sheets were designed for every module for police, the health sector, and the social sector. These can serve as handouts in a course or workshop and can be adapted to individual needs. Scenario-based learning, case studies and knowledge assessments for police, the health sector, and the social sector as well as an exemplary workshop concept for the various sectors can be adapted by trainers. As examples, we highlight our training videos, the risk assessment tool as scenario-based learning method, and an exemplary workshop concept for a 90 minute-medical student course with downloadable presentations that trainers can adapt.

\section{Training videos}

The training videos are about 1-2 minutes in length and summarise the most important aspects of each module. The used drawn figures were diversified by a graphic designer to include further gender and diversity aspects (Figure 4). 

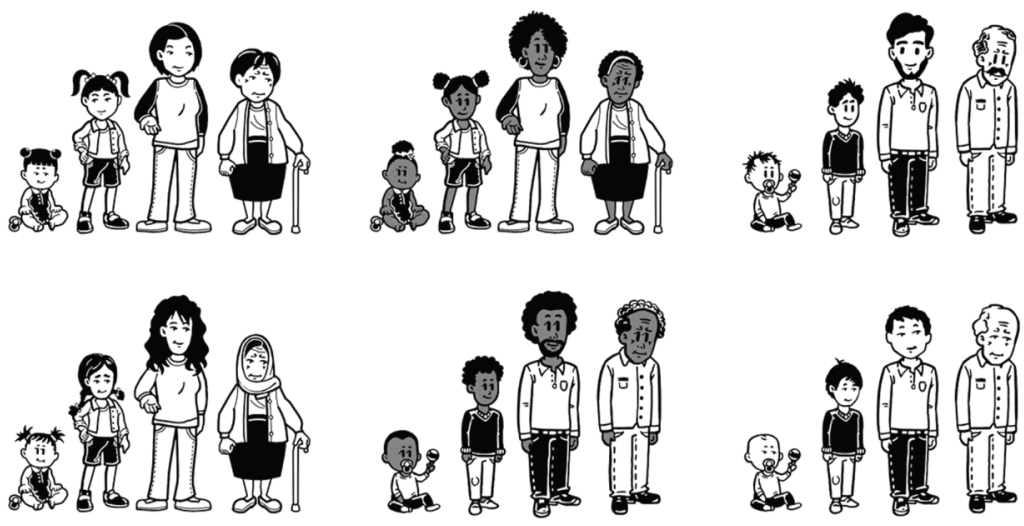

Figure 4: Examples of diversified drawings of victim groups

The videos are shared on IMPRODOVA's YouTube channel ${ }^{1}$ and cover the following topics:

\section{- Domestic violence in Health Services}

"Domestic violence in Health Services" is about the role of frontline responders in the medical sector. For many victims of domestic violence, health professionals are the first point of contact. This video explains what constitutes domestic violence, who can be a victim of domestic violence, and what may be the next steps if you suspect a patient has experienced domestic violence.

\section{- How to respond to a disclosure}

"How to respond to a disclosure" deals with the response and attitude when a victim discloses domestic violence. The key steps of a response to a disclosure, which include listening, communicating belief, validating the decision to disclose, emphasizing the unacceptability of violence, and offering support are explained in more detail.

\footnotetext{
${ }^{1}$ https://www.youtube.com/channel/UC998cREyGoT--daViEII2fQ
} 


\section{- What happens when you call the police?}

"What happens when you call the police?" looks at the role of police as frontline responder. For those affected by domestic violence, police officers are a key service in an emergency. The video reflects the responsibilities of police to investigate, to ensure the safety of those affected by domestic violence, and to offer help and reassurance.

\section{- What happens when you contact a women's shelter?}

"What happens when you contact a women's shelter?" is about women affected by domestic violence who are forced to leave their homes to be safe. In this video, the shelters' key elements of providing information, support and counselling are described.

\section{- Who is affected by domestic violence?}

"Who is affected by domestic violence?" questions the factors that lead to becoming a victim of domestic violence and explains the different forms of experience. The videos underline that there are many factors causing people to stay in abusive relationships although they are affected by domestic violence.

\section{- Who are the perpetrators of domestic violence?}

"Who are the perpetrators of domestic violence?" explains the factors that can play a role in persons when they are becoming abusive, and how perpetrator programmes can assist to stop abusive behaviours. In this video, it is highlighted that perpetrators are responsible for their actions and that an understanding of gendered inequalities in society is a key component in ending domestic violence.

\section{- Why is cooperation in cases of domestic violence important?}

In "Why is cooperation in cases of domestic violence important?", the emphasis is on frontline responders from health services, police and non-governmental organisations sharing the common goal of preventing further harm to those affected by domestic violence. The video points out why working together is the most effective way to tackle domestic violence for agencies. This includes a better 
provision of information and cooperation between professionals on individual cases and a supportive and empowering environment, so people affected by domestic violence feel confident to contact the police and other professionals.

\section{- The UN and its role in combating violence against women}

"The UN ant its role in combating violence against women" gives an overview of the UN resolutions dealing with combating violence against women. The video underlines that countries should take measures to prevent and prosecute acts of violence against women by intensifying efforts to raise awareness about domestic violence and violence against women, by providing training for all professionals and by offering specialised support for women and children affected by gender-based violence.

\section{- Domestic violence in times of disasters}

"Domestic violence in times of disasters" is based on the current situation with COVID-19. There are indications that domestic violence may have increased during the COVID-19 pandemic. In this video, it is explained how frontline responders can help those experiencing domestic violence during the COVID-19 pandemic and the quarantine ordinances. For example, services such as making text or online chat services available 24-7 may help those affected by domestic violence to access support more safely.

\section{Risk assessment tool}

The IMPRODOVA risk assessment integration module (RAIMO; see chapter 2), as an example for scenario-based learning, explains the entire risk assessment procedure for the specific case "Nora", a woman with an immigrant background suffering from intimate partner violence. RAIMO renders a comprehensive approach to risk assessment by demonstrating different risk factors and different approaches to identifying and responding to risk and gives a clear understanding of the specific roles and responsibilities of different agencies (e.g., police officers, social work and healthcare professionals, NGO workers, educators) who come into contact with victim-survivors and perpetrators. 


\section{Workshop and student course concepts}

The student course for medical students is designed as an interactive seminar with presentations for up to 16-20 students in 4 groups. Including preparation and concepts for group work it corresponds to a total of $28 \mathrm{~h} /$ à 45 min each in total. The preparation-phase for the students will start 14 days prior to the course and includes the completion of a home assignment discussing three quotes about domestic violence. The quotes help students to reflect about their current knowledge on DV and attitudes towards domestic violence. The responses given in the home assignments will be discussed at the beginning of the course. Themes discussed in the course are forms and dynamics of domestic violence, indicators for domestic violence, Istanbul convention/legal framework, interagency cooperation, communication, and risk assessment in cases of DV in multi-professional teams. The content of the course is based on the IMPRODOVA training platform and the corresponding modules for the health sector.

\section{Evaluation}

After the international platform as well as the German national platform with all related trainings materials was finalised, the IMPRODOVA training platforms were evaluated by various frontline responder groups to further optimise the training materials. Due to the COVID-19 pandemic, most training sessions needed to be organised online.

In the IMPRODOVA partner countries, students, course participants, teachers, and experts from the three sectors of police, health sector and social sector assessed the content by using a questionnaire tailored to the various frontline responder groups or by participating in structured (focus groups) interviews. A pre- and post-survey was conducted in Germany and in Finland, respectively. Socio-demographic characteristics, the assessment of the training platform and of individual modules as well as self-assessment with regard to the learning objectives and thematically relevant attitudes were investigated. 
Generally, the didactic concept of the training involved a general transfer of knowledge, and more specifically, an increase in competences on domestic violence including providing practical advice, and solutions to problems e.g., how to improve interagency collaboration. The overarching goal is that frontline responders will use the material for their (future) work and to optimise their response to domestic violence.

\section{Evaluation of the German training platform}

The whole English IMPRODOVA training platform and related materials were translated into German and adapted for the German context to have this as demonstrator of how a national version of the training platform can look like (https://training.improdova.eu/de/). This included an adaptation of the contents of the individual modules to the legal framework in Germany, but also a translation and adaptation of the individual training materials such as videos and case studies to the German context. The German IMPRODOVA training platform was evaluated in Germany and by Austrian students.

In Germany, medical students of the Westfalian-Wilhelms-University of Muenster attended the two-day clinical compulsory elective course "Domestic Violence in an International Context", based on the materials of the German training platform. The detailed agenda of the elective course is part of the IMPRODOVA training materials and is explained in more detail in chapter 4.2.4. The pre-survey in Muenster was conducted prior to the elective course, the post-survey after the completion of the elective course.

28 students completed both questionnaires. Students considered the intervention of domestic violence cases as an important part of the work of physicians, and they are motivated to work with victims of domestic violence in the future, but it is difficult for them to ask patients about domestic violence. This is not surprising, as most students have not received any curricular education or training on domestic violence prior to this newly established elective course in Muenster. Overall, students have a strong interest in the various issues related to domestic violence, but most students do not consider themselves competent regarding DV. Finally, against the background of these results, previous research was corroborated that there is a great need for training on domestic violence among medical students and that there is also interest on the part of the students. The comparison of the pre- and post-assessment 
indicated that the training platform, including its teaching materials, has contributed to a significant learning and competence progress of the students in all subject areas (Figure 6). Students felt much more competent after completion of the course.

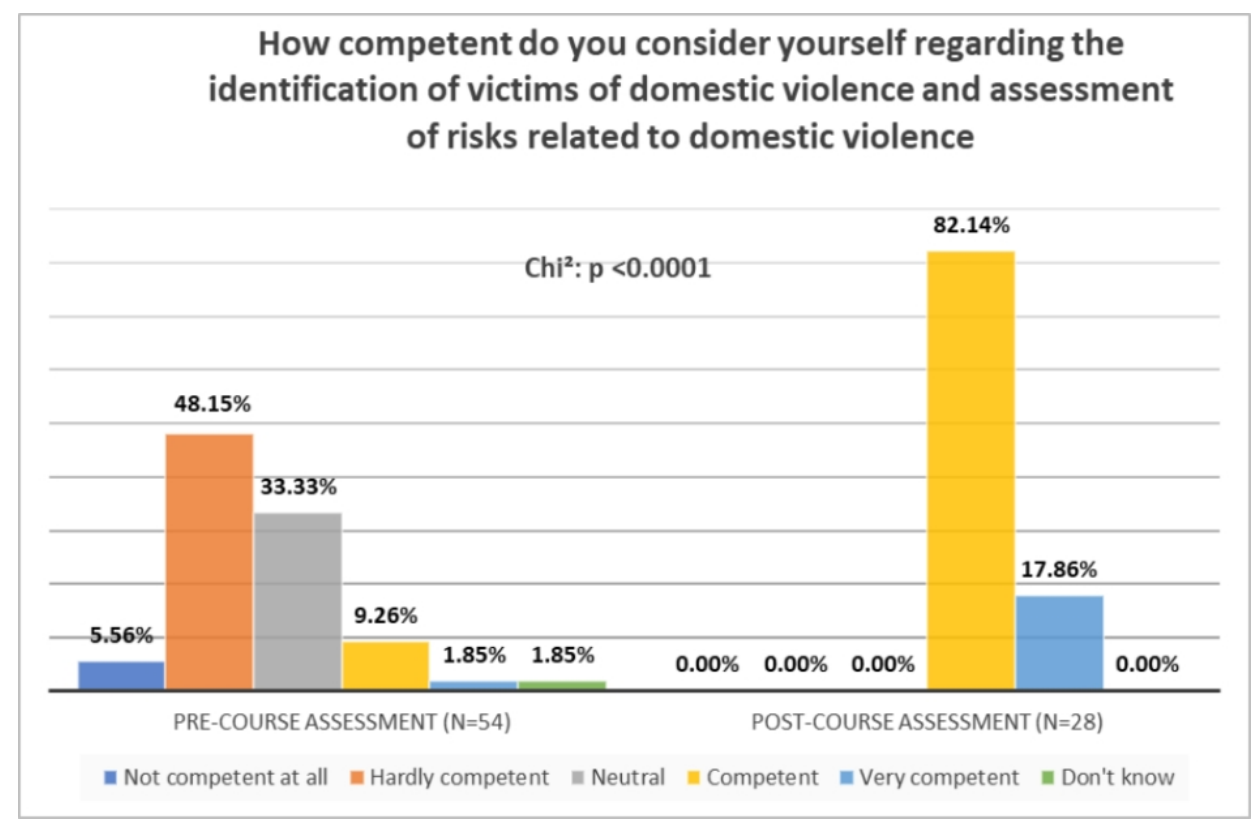

Figure 6: Reported competence of medical students $(n=28)$ in identifying victims of domestic violence and assessing risks related to domestic violence pre and after a student course on domestic violence.

The training platform was rated as very good overall by the medical students. They would recommend it to their fellow students and could imagine using it in the future. They also made some suggestions for improvement to make the training platform more attractive for students, which were implemented accordingly.

\section{Social sector students}

Data from two social sector students was collected in Austria. In general, the training materials were rated as good. Due to the small number of respondents, the evaluation of this sector is limited. 


\section{School teachers}

Three school teachers from different school forms in Germany, each, were invited to look at the materials on domestic violence in the school sector and provide feedback. The training materials were rated as very good. They were judged as being very important materials for the school sector, and being presented in a coherent, clear, and factual way. In particular, the concrete advice, such as the action steps (Figure 3), were found to be very helpful and concise. Based on the teachers' feedback, concrete examples of how to address children on the issue of domestic violence and how to strengthen the child's self-esteem were added after their feedback. The material was re-evaluated after the optimisation cycle and amendments were very well received.

\section{Police officers}

The section "Introduction - Police as frontline responder to domestic violence" on the German IMPRODOVA training platform was assessed by three police officers from Police Berlin; from their feedback it was learned that the introductory section would benefit from including more detailed information regarding police response to emergency calls and how to support officers in knowing hotspots and specifics of their work areas. Nevertheless, it was agreed that the platform has a great potential to deliver useful information for interested police officers and could possibly be used as an additional source in trainings after further optimising it in the future.

In Austria, 29 police officers were recruited with the support of the project partner BMI (Austrian Federal Ministry of the Interior) to participate in two-day training covering specific sections of the IMPRODOVA platform and material for the police. Although the individual modules and training materials were rated as good, the evaluation made clear police officers felt the Austrian national context of the provided information was lacking. In addition, the police officers wanted to have more pictures, quizzes and ficts and facts on the training platform. 


\section{Evaluation of the International IMPRODOVA training platform}

\section{Police students}

In Finland, an online training course with eleven police students at the Police University College of Finland was organised. The course was based on the IMPRODOVA training materials in English. Two online surveys, before and after training, were conducted with the police students to evaluate their change in attitudes and competencies. Ten students completed both questionnaires. The results of the pre- and post-survey indicated that the training platform and its material had a positive impact on students' competencies in relation to the prevention and detection of domestic violence. However, it was notified that some scenarios describe situations that are not necessarily very common in Finland. It was recommended to adapt the materials to the Finnish context.

\section{Medical sector}

Three educators in DV from Peru, Nigeria, and Australia, being members of Medical Women's International Association (MWIA), evaluated the section "Introduction - Domestic violence in the Health Sector". This section of the platform and the training platform as a whole were rated as done very well. It was highlighted that its length, structure, and clarity are very good.

\section{Police sector}

Two Hungarian police experts of the National University of Public Service assessed the section "Introduction - Police as frontline responder to domestic violence" and rated the training material as very good. These experts recommended to use the material not only as self-learning tool but in combination with a trainer supporting the learning process to enhance the impact of the material. They also suggested some slight improvements, e.g., making the section more user friendly by adding more pictures, which was implemented after the evaluation. 
In Finland, four police experts from the Police University College assessed the IMPRODOVA training platform as well. The evaluators also suggested to add some content for the police sector e.g., in the communication between police officers and victims and the treatment of perpetrators. For this reason, the police partners in the IMPRODOVA project were asked to add missing content.

\section{Social sector}

Six experts from the social sector in Finland assessed the IMPRODOVA training platform. In general, most of the suggestions given related to checking spelling mistakes and replacing unclear expressions with more accurate ones. Furthermore, the experts wanted additional content on the training platform, e.g., more content on children as victims of domestic violence. Following the evaluation, the entire training platform will be professionally checked with regard to the linguistic presentation of the content. Nevertheless, additional content will also be included.

\section{Summary}

To summarise, the training platform was positively rated by all evaluators. A prepost comparison of students showed a clear learning gain with regard to competence-based learning goals. Moreover, the training platform contributes to an increase in competence and to learning progress. Still, the evaluation also highlighted some gaps that were subsequently addressed to improve the usability of the platform even further.

The recommendations could be clustered into three areas: (a) Structure and usability; (b) Adaptation to the national and local context, (c) Suggestions for additional content.

\section{Structure and usability}

The majority of the respondents considered the IMPRODOVA training platform and its material as clearly structured. However, some recommended shortening certain modules. In addition, it was proposed to have more shorter sections instead of a long paragraph; it was also stressed that visualisations and summations of the main points may help the users to find respective content, e.g., including more 
images into the training platform could highlight important issues. This was addressed as much as possible. To facilitate finding contents, a table of contents with headings was integrated at the beginning of each module which is linked to the corresponding headings in the module. Also, a new search function was implemented to find content by keyword search.

\section{Adaptation to the national and local context}

The evaluation indicated that there is a strong need for national versions of the IMPRODOVA training platform. Many suggestions for improvement touched the lack of national context of the provided information. Firstly, due the differences in legislation and practises in Europe, some guidelines in the training material cannot be used across Europe without an adaptation to national conditions. Secondly, since some procedures vary from country to country, too universal descriptions may be misleading. This is certainly a disadvantage of presenting a European platform. Since it is not possible to adapt the material, especially the guidelines and procedures that are prescribed by legislation, regulations, and instructions, to national and local contexts within one platform, it was recommended to draft national versions of the training platform. The German version of the training platform was drafted as pilot demonstrator to show how a local adaption could be put into reality.

Originally, the introductions were labelled as " 15 minutes" sections. But we learned from the evaluation that most respondents misunderstood the concept of the " 15 minutes" sections. They expected to learn everything important to know in 15 minutes and therefore criticised missing points or simplifications, when in fact all content can be found in the corresponding modules. Unfortunately, most respondents never consulted the corresponding modules. Thus, the didactic concept for the "15 minutes" sections was adapted accordingly to made it clearer that it is only a short overview for those without any experience in DV, but one still needs to read the corresponding modules. For this reason, and to avoid misunderstandings in the future, we renamed the "15 minutes" sections into introductions. 


\section{Suggestions for additional content}

Supplementary content, in particular, the position of immigrant women and LGBTQ persons as victims of domestic violence were recommended to add by some evaluators. In addition, more detailed information about coercive control, internet abuse and cyber stalking as forms of violence were requested. There were also several suggestions for adding some more content that would describe the positions of children as victims and witnesses of domestic violence. Some also suggested that adding links to facilities and organisations supporting perpetrators would be useful for frontline responders as well as information about perpetrator programmes. Based on these recommendations given in the evaluations we added new content to such training materials, for instance, a section about domestic violence in the media, since media play an important role how DV and how victims are perceived in public. The impact of the COVID-19 pandemic on DV was also added, as well as training materials tailored to school teachers. We added also interviews on our platforms as suggested by the evaluators. For example, one participant of the German medical student course who often works as translator in cases of DV, conducted an interview with a member of a working group specialised on refugees and migrants as victims of domestic violence. The interview being published on the German IMPRODOVA training platform describes how they come into contact with victims, what kind of support is offered, what challenges are present, and the aims of the support given by them. The English translation of the interview was published as a blog on the IMPRODOVA website. ${ }^{2}$ Furthermore, the training platform was improved by including more self-learning assessments and teaching tools (e.g., more quizzes, case studies on specific topics, etc.). Since the IMPRODOVA training platform is a living document, new content will be continuously added.

While all the recommendations have their own merits, one should not forget that the IMPRODOVA training platform is a demonstrator only and it is not possible to address all suggestions in the time given and the available resources.

\footnotetext{
2 https://improdova.eu/blog/detail.php?we_objectID $=214$
} 
All in all, the evaluation results indicated that the IMPRODOVA training platform can be successfully used for self-learning. Likewise, materials are also suitable for integrating in an existing course or can be used for a workshop and provide a deeper understanding of domestic violence and improve frontline response.

\section{References}

Herbinger, P. L., Leonhardmair, N. \& Neunkirchner, M. (2020). European legislation to fight domestic violence. European Law Enforcement Research Bulletin, (20), 141-154. http://bulletin.cepol.europa.eu/index.php/bulletin/article/view/415/339

Houtsonen, J. (2020). Policing Domestic Violence: Strategy, Competence, Training. European Law Enforcement Research Bulletin, (19), 135-151.

https://bulletin.cepol.europa.eu/index.php/bulletin/article/view/417/318

Pfleiderer, B. \& Sondern, L. (2020). Why the integration of sex and gender aspects will improve Domestic Violence Risk Assessment. European Law Enforcement Research Bulletin, (20), 155-165. http://bulletin.cepol.europa.eu/index.php/bulletin/article/view/413

Pfleiderer, B. \& Sondern, L. (2021). The Challenge of Involving Medical Doctors as Important Frontline Responders in Fighting Domestic Violence. European Law Enforcement Research Bulletin, (21), 141-150. https://bulletin.cepol.europa.eu/index.php/bulletin/article/view/414

Vogt, C. (2020). Interagency Cooperation. European Law Enforcement Research Bulletin, (19), 153-163. http://bulletin.cepol.europa.eu/index.php/bulletin/article/view/412 